\title{
Clima, cambio climático y riesgos climáticos en el litoral mediterráneo. Oportunidades para la geografía*
}

\section{Jorge Olcina}

Universidad de Alicante. Departamento de Análisis Geográfico Regional y Geografía Física jorge.olcina66@gmail.com

Recibido: noviembre de 2019

Aceptado: noviembre de 2019

Publicado: enero de 2020

\section{Resumen}

La climatología es la rama que desarrolla en mayor grado el principio rector de la geografía: el estudio de las relaciones entre el medio y el ser humano, así como de sus diferentes manifestaciones sobre la superficie terrestre. La climatología española compite en la actualidad en igualdad de condiciones con el análisis climático internacional. Ha incluido nuevos planteamientos teóricos y métodos de trabajo que proporcionan resultados publicados en revistas y en monografías de impacto. Uno de los temas principales de la investigación española en dicho ámbito es el cambio climático actual y los efectos que ejerce en los elementos atmosféricos. El litoral mediterráneo es un buen laboratorio para profundizar en esta cuestión, puesto que ya manifiesta consecuencias que, si mantienen su tendencia actual, pueden comportar efectos en las actividades económicas y en la propia ocupación del territorio. En el presente artículo se propone una agenda de trabajo para que, en este contexto, la climatología española se convierta en la rama protagonista de la investigación y la docencia geográfica española en los próximos años.

Palabras clave: tiempo; clima; climatología; cambio climático; litoral mediterráneo

* El presente texto ha sido preparado a partir de la conferencia impartida por el autor en la Universitat de Girona, con motivo de los actos de celebración del Día de la Geografía (abril de 2019), bajo la organización del Departamento de Geografía de dicha universidad y la revista Documents d'Anàlisi Geogràfica, que editan los departamentos de Geografía de las universidades Autónoma de Barcelona y de Girona. 
Resum. Clima, canvi climàtic i riscos climàtics al litoral mediterrani. Oportunitats per a la geografia

La climatologia és la branca que desenvolupa el principi rector de la geografia en un grau més elevat: l'estudi de les relacions entre el medi i l'ésser humà, com també de les diferents manifestacions que realitza sobre la superfície terrestre. La climatologia espanyola competeix actualment en igualtat de condicions amb l'anàlisi climàtica internacional. Ha inclòs plantejaments teòrics i mètodes de treball nous que proporcionen resultats publicats en revistes i monografies d'impacte. Un dels temes principals de la investigació espanyola en aquest àmbit és el canvi climàtic actual i els efectes que exerceix en els elements atmosferics. El litoral mediterrani és un bon laboratori per aprofundir més en aquesta qüestió, atès que ja manifesta conseqüències que, si mantenen la seva tendència actual, poden comportar efectes en les activitats econòmiques i en la pròpia ocupació del territori. Al present article s'hi proposa una agenda de treball perquè, en aquest context, la climatologia espanyola es converteixi en la branca protagonista de la investigació i la docència geogràfica espanyola en els propers anys.

Paraules clau: temps; clima; climatologia; canvi climàtic; litoral mediterrani

Résumé. Climat, changement climatique et risques climatiques sur le littoral méditerranéen: opportunités pour la géographie

La climatologie est la branche géographie qui développe le plus le principe directeur de cette dernière : l'étude des relations entre l'environnement et l'être humain et leurs différentes manifestations à la surface de la Terre. La climatologie espagnole est actuellement en concurrence avec la recherche internationale sur le climat. Elle a inclus de nouvelles approches théoriques et des méthodes de travail qui fournissent des résultats publiés dans des revues et des monographies à fort impact. L'un des principaux thèmes de la recherche sur le climat espagnol est le changement climatique actuel et ses effets sur les éléments atmosphériques. La côte méditerranéenne constitue un bon laboratoire de recherche sur cette question qui manifeste déjà des conséquences qui, si elles maintiennent leur tendance actuelle, peuvent avoir des effets sur les activités économiques et sur l'occupation du territoire lui-même. Un programme de travail est proposé pour que la climatologie espagnole, dans ce contexte, devienne la principale branche géographique de la recherche et de l'enseignement géographiques espagnols au cours des prochaines années.

Mots-clés: temps; climat; climatologie; changement climatique; côte méditerranéenne

Abstract. Climate, climate change and climate risks in the Mediterranean litoral: Opportunities for geography

Climatology is the branch of geography that, to a greater extent, responds to the main objective of the field: the study of the relationships between the environment and human beings and their different manifestations on the earth's surface. Spanish climatology is currently competing on equal terms with international climate research through the contribution of new theoretical approaches and methods and the dissemination of results in high-impact international journals. One of the main topics of Spanish climate research is the current climate change and its effects on atmospheric elements. The Mediterranean coast is a good laboratory for investigating an issue whose consequences are already being felt and, if the current trend is maintained, can have effects on economic activities and spatial occupation. In this context, a work agenda is proposed for Spanish climatology to become the main geographical branch of Spanish geographic research and teaching in the next years.

Keywords: weather; climate; climatology; climate change; Spanish Mediterranean coast 


\section{Sumario}

1. Nuevos planteamientos en los estudios del clima desde la geografía española

2. Cambio climático y riesgos climáticos en el litoral mediterráneo. Evidencias e incertidumbres: una oportunidad para la geografía
3. ¿Hacia dónde deben ir los estudios del clima?: Una agenda para la climatología española en el contexto actual de calentamiento global

Agradecimientos

Referencias bibliográficas

Es el conjunto de variaciones atmosféricas que afectan nuestros órganos de una manera sensible.

(Definición de clima, Alexander von Humboldt, Cosmos, Libro I, 1845)

\section{Nuevos planteamientos en los estudios del clima desde la geografía española}

La climatología, disciplina geográfica encargada del estudio de los tiempos y los climas que se desarrollan sobre la superficie terrestre, atraviesa un momento de actividad constante, en ocasiones acelerado pero entendible dentro del contexto ambiental actual. Los efectos previstos del actual proceso de calentamiento global que se registra en la troposfera terrestre, señalados ya en la década de 1980 por la actual hipótesis de cambio climático por efecto invernadero de causa antrópica, ha abierto enormes posibilidades de investigación que se han unido a la labor habitual de descripción de fenómenos y elementos del clima en el espacio geográfico. Por dicho motivo proliferan en la actualidad los estudios climáticos de aspectos muy variados que presentan los índices de las revistas científicas de impacto en el ámbito de las ciencias atmosféricas. E incluso ha motivado el nacimiento de nuevas publicaciones periódicas (por ejemplo: Nature Climate Change) que han venido a cubrir el amplio espacio de investigación generado por el proceso actual de calentamiento global.

Entendido como el ambiente permanente que percibe y vive el ser humano y que se compone de manifestaciones atmosféricas diarias, a veces extremas, el clima es uno de los elementos principales del medio físico, junto al relieve, en la configuración de los espacios geográficos. Es un componente fundamental para la conformación de paisajes vegetales, la distribución de ecosistemas animales y la propia vida de los seres humanos en la Tierra. Además, los climas tienen un componente salutífero, diferente en cada variedad, que hace más o menos confortable la estancia en los territorios.

El estudio del clima es una de las ramas de la geografía más tempranamente desarrollada por el ser humano desde la antigüedad. Las primeras cartografías del espacio habitable y del espacio conocido encuentran en dos elementos del 
clima (temperatura e insolación) el sistema de referencia espacial básico para la localización de áreas y ciudades (Olcina, 1996). Y desde sus inicios el estudio del clima ha tenido una estrecha relación con el ser humano, puesto que no era un componente meramente físico del medio. El clima permitía - condicionaba-, o no, las actividades económicas y justificaba el tipo de vivienda y la ubicación de los núcleos de población.

En la actualidad la capacidad técnica del ser humano ha hecho que el clima no sea un elemento determinante de su actividad sobre la superficie terrestre. $\mathrm{Al}$ contrario, las personas han desarrollado capacidad para poder alterar ese ambiente permanente, al incorporar, como sabemos, elementos - gases - que generan modificaciones en el balance energético planetario, verdadera causa del clima terrestre y de la distribución de sus modalidades sobre el espacio geográfico.

Hace ahora una década, en el marco del X Congreso Internacional de Geocrítica, se realizó un balance sobre la evolución y los cambios de las investigaciones sobre riesgos naturales (Olcina, 2008). Entonces se apuntaban algunas modificaciones conceptuales y de método en la consideración de los riesgos naturales como materia de investigación con sentido aplicado en la disciplina geográfica. Básicamente los cambios venían motivados por el paso de las aproximaciones teóricas a la práctica del análisis de riesgo motivada por la aparición de normativa europea, estatal y autonómica que contemplaba la incorporación de estos estudios en los procesos de planificación territorial. En este contexto, la reunión de la Asociación Española de Climatología, celebrada en Zaragoza en 2007, había abordado aspectos teóricos y de método que entonces dominaban los trabajos de la climatología española, con un tema que iniciaba su influencia en ellos: el calentamiento global (Cuadrat y Martín Vide, 2007). Un año después, el grupo de climatología de Tarragona coordinará una obra de referencia sobre los efectos regionales del cambio climático en España (Sigró et al., 2008). Un tiempo más tarde, en el congreso del Grupo de Didáctica de la AGE, celebrado en Alicante (2015), se reflexionó sobre la manera de transmitir los aspectos básicos de la climatología, los riesgos climáticos y el calentamiento global en los niveles educativos no universitarios, señalando la importancia de explicar, desde el rigor de los datos de investigación, estas cuestiones haciendo digeribles a las generaciones jóvenes mecanismos y fenómenos que pueden condicionar su presente y su futuro en el espacio geográfico (Sebastiá-Alcaraz, y Tonda-Monllor, 2017).

En apenas una década han surgido nuevos temas de estudio y otros se han consolidado en materia de clima, calentamiento global y de sus riesgos asociados, que motivan reflexión sobre el papel de la geografía en este contexto. Una disciplina, la geografía, que, tras décadas de incorporación de aproximaciones teórico-filosóficas, vive unos momentos de austeridad epistemológica (Olcina y Baños, 2004) sin duda generados por los cambios acelerados que impone el actual proceso de globalización, con todas sus alteraciones socioeconómicas y culturales (Massey, 2004; Murray, 2005; Nederveen Pieterse, 2015). Pero se ha sabido adaptar para afrontar los temas nuevos que han 
surgido en este período de tiempo y que tienen en el cambio climático y en sus efectos ambientales, socioeconómicos y territoriales un eje de reflexión y acción de primer orden.

En esencia, los estudios que se realizan en la actualidad en nuestro país en el ámbito de la geografía sobre tiempo y clima, sobre su comportamiento ordinario y extraordinario y sobre los cambios que ya se perciben en el funcionamiento de algunos de sus elementos principales (temperatura, precipitación, viento) se caracterizan por:

Un conocimiento de las técnicas y de los métodos de tratamiento estadístico de los datos que aseguran la internacionalización de los resultados de análisis.

Una elaboración de cartografía climática precisa gracias al manejo de sistemas de información geográfica.

Una visión amplia de los procesos y de los fenómenos estudiados que permite ofrecer propuestas prácticas de actuación a la vista de los resultados obtenidos.

Una integración de investigaciones en planes de actuación de las administraciones en materia climática (cambio climático) o de riesgos naturales (inundaciones, sequías).

Siguiendo lo que se realiza a nivel internacional, las temáticas de estudio se han diversificado y especializado. Y, a través de análisis competitivos o contratos de investigación de financiación diversa, se ha dado respuesta a una serie de acciones y de procesos relacionados con el comportamiento de la atmósfera o del elemento agua que se han desarrollado o manifestado en las últimas dos décadas (tabla 1).

Se analiza el comportamiento de oscilaciones de circulación general (Martín Vide y López Bustins, 2006; López Bustins et al., 2008; Redolat et al., 2018) o del proceso de calentamiento global en nuestro territorio (Brunet et al., 2007; Sigró et al., 2009; Martín Vide y Gallego, 2009; Olcina, 2017; Miró et al., 2012); se aplican nuevos métodos de tratamiento estadístico para la obtención de patrones de funcionamiento de los elementos climáticos (González-Hidalgo et al., 2009; Miró et al., 2016, Serrano Notivoli, 2017). No faltan las aproximaciones con finalidad aplicada en el análisis de los extremos atmosféricos y sus efectos derivados: inundaciones, sequías y temporales (Pérez Morales et al., 2016; García Marín y Calvo, 2008). Se abordan, asimismo, estudios comparados de un riesgo climático para tratar la mejora de los indicadores de estado y aviso, como en el caso de las sequías (Peña-Gallardo et al., 2016; Vicente-Serrano et al., 2019), y se han elaborado aproximaciones muy bien fundadas para el conocimiento de los climas del pasado a partir del estudio de proxy-data (Tejedor, 2017; Gil Guirado y Pérez Morales, 2019). Algunos geógrafos del litoral mediterráneo han participado, asimismo, en el proyecto ESPON-Climate, auspiciado por el Observatorio en Red de la Ordenación del Territorio, que ha tenido como objetivo estudiar los aspectos sociales y económicos relacionados con el impacto del calentamiento térmico planetario en el ámbito europeo (Saurí et al., 2013). 
Tabla 1. Aportaciones de la climatología española en la planificación de recursos y riesgos del clima y del agua (2000-2019)

\begin{tabular}{|c|c|c|}
\hline Elemento & Acciones y procesos & Aportaciones de la climatología española \\
\hline Clima & $\begin{array}{l}\text { - Informes de cambio climático (IPCC, } \\
\text { 2007, 2013-2014). } \\
\text { - Informe de Cambio Climático España } \\
\text { (2005). } \\
\text { - Informes autonómicos de cambio } \\
\text { climático (Cataluña y País Vasco). } \\
\text { - Planes de adaptación al cambio } \\
\text { climático. } \\
\text { - Episodios intensos de contaminación } \\
\text { atmosférica en grandes ciudades. } \\
\text { - Proliferación de asociaciones de } \\
\text { aficionados a la meteorología. } \\
\text { - Objetivos de desarrollo sostenible. }\end{array}$ & $\begin{array}{l}\text { - Estudios sobre elementos climáticos } \\
\text { a diferentes escalas. } \\
\text { - Estudios sobre dinámica atmosférica } \\
\text { (procesos de conexión isobárica: } \\
\text { ENSO, NAO, WeMO). } \\
\text { - Participación en informes internaciona- } \\
\text { les, nacionales y autonómicos de } \\
\text { cambio climático. } \\
\text { - Estudios sobre efectos del cambio } \\
\text { climático: manifestación de evidencias } \\
\text { con datos instrumentales. } \\
\text { - Estudios sobre contaminación } \\
\text { atmosférica. } \\
\text { - Estudios sobre alternativas energéticas } \\
\text { (eólica, solar). } \\
\text { - Participación en planes de adaptación } \\
\text { al cambio climático. } \\
\text { - Enfoques relacionados con los ODS } \\
\text { para la incorporación del clima y sus } \\
\text { manifestaciones extremas en procesos } \\
\text { territoriales. } \\
\text { - Participación de geógrafos en asocia- } \\
\text { ciones de aficionados a la meteorología. }\end{array}$ \\
\hline Agua & $\begin{array}{l}\text { - } \text { Directiva marco del agua (60/2000). } \\
\text { - Ley de aguas y RDPH (2001, mod. } \\
\text { - Ley del Plan Hidrológico Nacional } \\
\text { (2001, mod. 2005). } \\
\text { - Elaboración de los nuevos planes } \\
\text { de demarcación hidrográfica. } \\
\text { - Directiva de gestión del riesgo de } \\
\text { inundaciones (60/2007). } \\
\text { - Episodios importantes de inundación. } \\
\text { - Cartografías de riesgo. Creación del } \\
\text { SNCZI. } \\
\text { - Planes de gestión de sequías. } \\
\text { - Planes autonómicos de reducción } \\
\text { de riesgo (inundaciones). } \\
\text { - Objetivos de desarrollo sostenible. }\end{array}$ & $\begin{array}{l}\text { - Estudios sobre planificación y gestión } \\
\text { del agua: a favor y en contra de las } \\
\text { medidas del PHN. } \\
\text { - Creación de plataformas para la gestión } \\
\text { sostenible y nueva gobernanza del agua } \\
\text { (nueva cultura del agua). } \\
\text { - Elaboración de estudios y cartografía } \\
\text { de riesgos de inundación. } \\
\text { - Estudios sobre peligrosidad y vulnera- } \\
\text { bilidad. Nuevo enfoque en el análisis } \\
\text { de riesgo (papel del ser humano como } \\
\text { creador de territorios de riesgo). } \\
\text { Nuevos conceptos (resiliencia). } \\
\text { - Estudios sobre relación entre cambio } \\
\text { climático y recursos de agua (con } \\
\text { finalidad de planificación). } \\
\text { - Incorporación de los extremos } \\
\text { hidrológicos como componentes de la } \\
\text { infraestructura verde en la planificación } \\
\text { territorial. }\end{array}$ \\
\hline
\end{tabular}

Fuente: elaboración propia. 
En relación con la planificación de los riesgos del agua, han sido abundantes las contribuciones realizadas por la geografía española que comparten, todas ellas, la idea del incremento del riesgo ocurrido en las últimas décadas en virtud de actuaciones humanas indebidas o imprudentes sobre los territorios en relación con los recursos hídricos existentes en los mismos. Sin duda, las inundaciones han merecido una atención mayor. Se han valorado los cambios en aspectos conceptuales (Calvo, 2001; Saurí y Ribas, 2006; Olcina, 2008), la importancia de la cartografía de riesgo (Pérez Morales, 2012; Olcina, 2012), la eficacia de las obras estructurales de defensa (Pérez Morales et al., 2015), la necesidad de fundamentar los estudios de riesgo de inundación con serios análisis hidrológicos e hidrogeomorfológicos (Segura, 2009; Camarasa y Soriano, 2008), la mejora de los estudios de peligrosidad (Perles y Cantarero, 2010), el análisis de la vulnerabilidad como elemento fundamental para el estudio del incremento contemporáneo del riesgo (Calvo, 2003; Perles y Mérida, 2010) y las posibilidades de reducción del riesgo desde la restauración fluvial como opción sostenible de respeto del territorio fluvial (Ollero, 2015; Ibisate et al., 2015). Asimismo, no han faltado aproximaciones dedicadas al análisis de las sequías (Paneque, 2015; Pita, 2014; García Marín, 2008). Y se han elaborado aproximaciones donde se destaca el valor del conocimiento histórico del riesgo de inundación y sequía para poder valorar con rigor la situación actual existente en los territorios afectados por eventos extremos (Barriendos, 2012; Martín Vide, 2007; Giménez Font, 2009). Por su parte, la necesidad de incorporar en la planificación de los recursos y riesgos del agua los nuevos escenarios previstos de cambio climático y sus efectos en las precipitaciones, ha merecido asimismo aproximaciones desde la geografía española (De Luis et al., 2010; Miró Pérez, 2014).

Han aparecido también estudios orientado a la explicación de los tiempos y de los climas en educación primaria o secundaria (Martínez Fernández y Olcina Cantos, 2019). En esta línea de trabajo se han realizado estudios sobre la percepción del clima en algunos territorios y la recuperación de tradiciones orales, con ánimo de que puedan ser incorporadas como materia de prácticas didácticas en niveles universitarios y no universitarios (Morote y Moltó, 2017; Guerra Ángel, 2018). En este contexto, se han editado algunas monografías de climatología regional que aúnan el análisis científico de procesos y elementos climáticos con una visión didáctica en la presentación de los mismos. Es un modo de aproximar la climatología al gran público, sin olvidar el rigor necesario en la explicación de datos y tendencias (Martí Ezpeleta et al., 2019; Olcina y Moltó, 2019).

En la actualidad, las investigaciones de la climatología geográfica española compiten sin complejos con las del ámbito internacional, como demuestra el volumen de publicaciones en revistas de temática atmosférica o estrictamente climática durante los últimos años. Las reuniones periódicas de la Asociación Española de Climatología y los talleres del Grupo de Climatología de la AGE son una muestra de la dinámica que muestran los grupos de investigación en climatología que existen en nuestro país. En este sentido, hay algunos que destacan en los últimos años por su labor de investigación, a modo de locomotora 
que orienta el quehacer del resto de estudios dentro de la disciplina geográfica: Barcelona, Zaragoza-IPE, Valencia, Sevilla, Alicante, Málaga, La Laguna-Las Palmas y Santiago de Compostela. Y resultan muy fluidas las relaciones con la investigación que se desarrolla en grupos existentes en departamentos universitarios de física, historia, biología y geología, con la propia AEMET u otros organismos autonómicos de análisis climático y meteorológico, así como con la OMM y con grupos europeos, americanos o australianos.

En el comienzo de la tercera década del siglo xxi la climatología española es una de las ramas geográficas con una dinámica de investigación y publicación más intensa. Ha sabido integrar el uso de las nuevas tecnologías y de los tratamientos estadísticos en los análisis de datos, muestra compromiso con la investigación del proceso de calentamiento global, desgranando el comportamiento de los elementos climáticos en los diferentes ámbitos territoriales y, sobre todo, apuesta por la precisión en sus estudios.

A ello se une la oportunidad que supone la crisis climática actual, originada por el proceso de calentamiento térmico de causa antrópica que registra el planeta. Esta cuestión que cada vez está cobrando mayor protagonismo en las investigaciones climáticas de nuestro país puede convertirse en un eje de trabajo principal para el conjunto de la disciplina geográfica, debido a las repercusiones que este proceso está teniendo, y va a seguir manifestado en todos los elementos integrantes del medio y de la sociedad. Y ello bajo el liderazgo de la climatología española, que es la que debe ir mostrando la realidad de los análisis y de los estudios sobre esta cuestión a partir de sus investigaciones. Es un reto al que debe responder con rigor.

\section{Cambio climático y riesgos climáticos en el litoral mediterráneo. Evidencias e incertidumbres: una oportunidad para la geografía}

Como se ha indicado, uno de los aspectos que más ha dinamizado la investigación climática española en la última década ha sido el estudio de los efectos del proceso de calentamiento térmico actual en los territorios españoles, y en este sentido los resultados comienzan a ser concluyentes a la vista del tratamiento de los datos climáticos. El litoral mediterráneo presenta, así, unos rasgos propios que singularizan los efectos del cambio climático actual en este espacio geográfico. Fundamentalmente, la presencia de un mar frente a sus costas que manifiesta un proceso de calentamiento rápido en las últimas décadas condiciona el funcionamiento de los dos elementos climáticos más importantes para la caracterización de los tiempos y los climas (temperaturas y precipitaciones).

Las condiciones atmosféricas actuales en la fachada mediterránea española ya no son las mismas desde hace tres décadas. Es un hecho constatado con datos científicos. El efecto del calentamiento global planetario en las escalas regionales ha pasado de ser un tema de creencias a una cuestión de evidencia científica basada en registros instrumentales. En la década de 1980, cuando se lanzó la hipótesis del calentamiento global por efecto invernadero de causa antrópica (emisiones de gases a la atmósfera), se podía dudar, tal vez, 
del resultado de la misma. Entonces no se manifestaban aún tendencias claras y algunos datos resultaban, incluso, contradictorios. Pero hoy, cuando está finalizando el segundo decenio del siglo xxi, las evidencias son cada vez mayores. Los datos están ahí para corroborar lo que son propensiones manifiestas. En el litoral mediterráneo hay tres procesos que tienen relación estrecha con el mecanismo planetario de cambio climático: 1) las variaciones estacionales de las precipitaciones y la intensificación de los chubascos; 2) el incremento de la temperatura media y, en especial, del calor nocturno, manifestado en las denominadas «noches tropicales» $\left(\mathrm{T}^{\mathrm{a}}>20^{\circ} \mathrm{C}\right.$ ), y 3 ) el señalado calentamiento de las aguas del mar Mediterráneo occidental en su sector central (mar de Argel y mar Balear), que está, sin duda, en el origen de las dos alteraciones anteriores señaladas de las precipitaciones y las temperaturas. Los tres están ya corroborados en datos científicos. Ya no son supuestos; son manifestaciones claras de cambio climático en el litoral mediterráneo español.

El primer proceso, los cambios en la precipitación, es el que suscita más incertidumbre a medio y a largo plazo, ya que no hay que olvidar que la irregularidad de las lluvias es uno de los rasgos distintivos de los climas del litoral mediterráneo. A nivel general, en las principales series climáticas entre Girona y Málaga no se aprecia una tendencia clara de disminución generalizada de las precipitaciones, aunque sí en la distribución e intensidad de las mismas, especialmente en las áreas próximas al mar. Por tanto, no llueve menos o ese descenso, de momento, es poco significativo e incluso en algunas comarcas se observan tendencias al alza en las precipitaciones registradas en las tres últimas décadas. Lo que sí se registra es que llueve de forma diferente. Desde el comienzo del siglo XXI se está observando que las precipitaciones de origen convectivo (especialmente aquellas asociadas a la presencia de situaciones de "gotas frías» en capas medias altas de la troposfera) cobran cada vez más importancia, frente a las precipitaciones frontales de origen atlántico, lo que sugiere que se están produciendo cambios en la circulación atmosférica (figura 1). Son cada vez más numerosos los estudios que señalan que la pérdida de velocidad de la corriente en chorro (en este caso, el jet polar del hemisferio norte) estaría provocando un importante incremento de episodios adversos (olas de calor y de frío, sequías intensas y lluvias torrenciales) en latitudes medias, donde se localiza la región mediterránea. Este hecho estaría ocasionado por el registro de un menor gradiente térmico entre las franjas de latitud como consecuencia del calentamiento global, que implicaría una menor velocidad de la corriente en chorro. Algún estudio ha señalado que la velocidad media de la corriente en chorro polar se habría reducido un $14 \%$ desde $1980^{1}$. Esto implica una mayor

1. Uno de los estudios más recientes es el realizado por Jennifer A. Francis, de la Universidad de Rutgers, y Stephen J. Vavrus, de la Universidad de Wisconsin-Madison, recuperado el mes de agosto de 2019, de <https://pdfs.semanticscholar.org/be1b/795c504d2fd9f3ad3a5 2a758381ccc76350b.pdf>. Véase también F. MARTín León (2019), «Los inviernos serán más cálidos, pero también con irrupciones más frías", Revista del Aficionado a la Meteorología (febrero), recuperado el mes de agosto de 2019, de <https://www.tiempo.com/ram/507091/ los-inviernos-seran-mas-calidos-pero-tambien-con-irrupciones-mas-frias/>. 
Figura 1. Evolución y tendencias de episodios de precipitaciones de alta intensidad horaria en el observatorio de Palma de Mallorca, 1977-2016

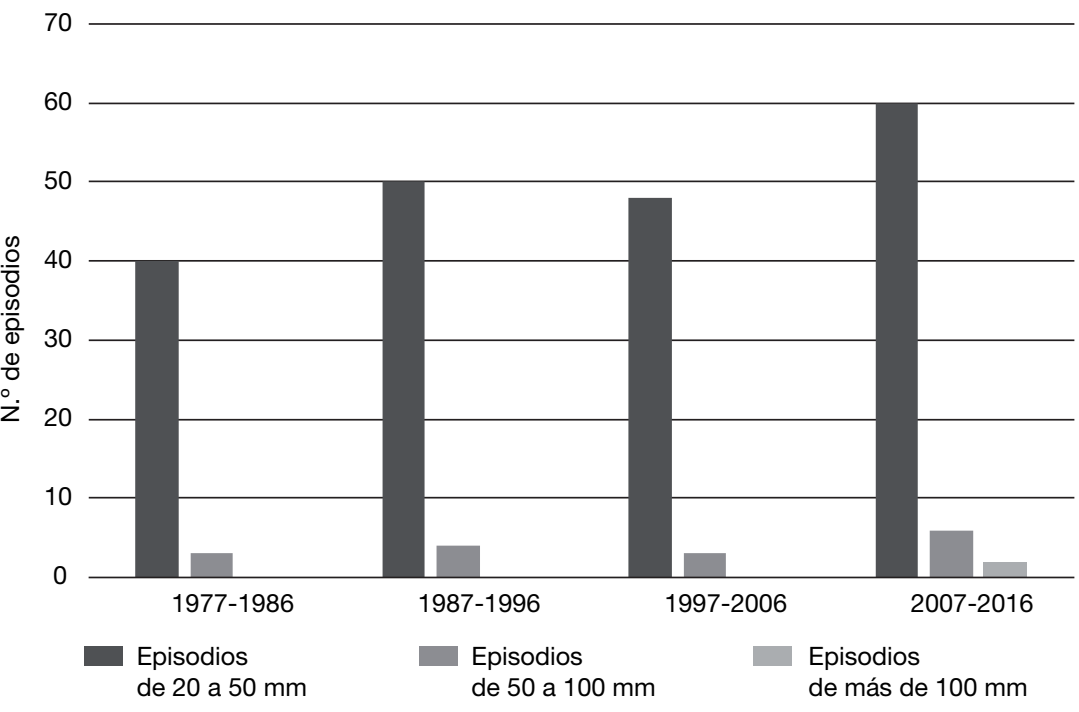

70

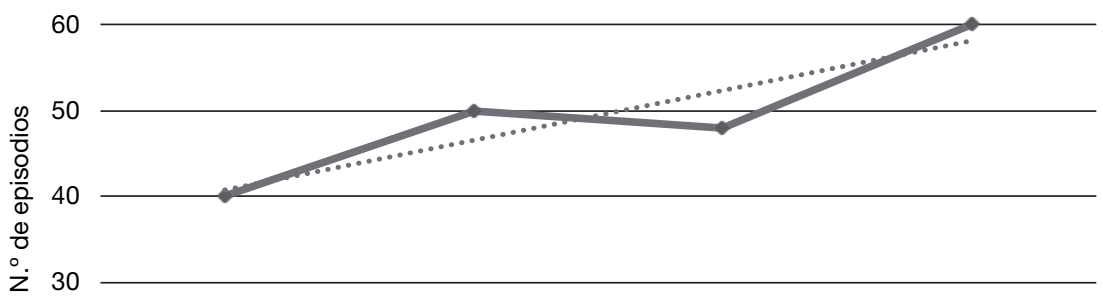

20

10

0

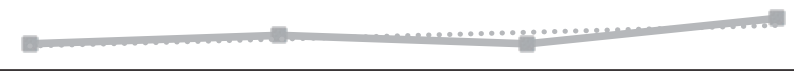

1977-1986

1987-1996

1997-2006

$2007-2016$

- Episodios de 20 a $50 \mathrm{~mm}$

Episodios de 50 a $100 \mathrm{~mm}$

Tendencia episodios de 20 a $50 \mathrm{~mm}$

Tendencia episodios de 50 a $100 \mathrm{~mm}$

Fuente: elaboración propia a partir de los datos de AEMET. 
ondulación del chorro, es decir, la generación más frecuente de ondas planetarias (crestas y vaguadas) con desplazamientos más rápidos de masas de aire cálido hacia latitudes septentrionales y de aire polar o ártico hacia el sur. Y las proyecciones señalan que esta situación será la habitual en los próximos años.

Otro aspecto a tener muy en cuenta es que las precipitaciones de intensidad horaria se presentan en cualquier estación del año. No se limitan al otoño, como tradicional estación del año de riesgo. Se producen eventos que rondan o superan los $100 \mathrm{~mm}$ en apenas una o dos horas, en cualquier mes. Incluso en verano, especialmente en la segunda quincena del mes de agosto, se aprecia un aumento de la torrencialidad en el litoral del golfo de Valencia, lo que está asociado a eventos de las denominadas "lluvias cálidas», síntoma del proceso de calentamiento intenso que experimenta el sector balear del mar Mediterráneo en este momento del año, que llega a alcanzar valores «tropicales» (27-28 ${ }^{\circ} \mathrm{C}$ en la temperatura superficial marina).

Estos cambios en las precipitaciones no se reflejan solo en las lluvias, sino también en las nevadas. Se da el hecho aparentemente paradójico de que mientras disminuye el número medio anual de días con heladas en consonancia con el proceso general de calentamiento térmico, aumentan en algunas zonas de la montaña mediterránea los días de nevada. Esto está en relación con los movimientos de masas de aire más enérgicos a que conduce una atmósfera más cálida. De manera que no son procesos contrapuestos, sino resultado del mismo fenómeno de calentamiento global. Así, por ejemplo, en la montaña de Alicante se aprecia un aumento significativo del número y espesor de las nevadas desde el año 2000. Asimismo, se desarrollan «nevadas de alta intensidad horaria» acompañadas de aparato eléctrico, en episodios que acumulan importantes espesores en pocas horas. Es el caso de las registradas en enero de 2017 en las provincias de Murcia y Alicante o de las nevadas «intensas» registradas en la propia ciudad de Barcelona en los últimos años (marzo de 2010 y febrero de 2018). En el extremo contrario las precipitaciones asociadas a la circulación zonal o las conocidas como «tormentas de verano» tienden a perder importancia en el total acumulado anual, tendencia que deberá ir confirmándose en los próximos años (Olcina y Moltó, 2019).

En primavera las precipitaciones tienden a perder terreno a favor del otoño. Esto es especialmente significativo en el extremo meridional del Sistema Ibérico, donde tienen su nacimiento algunos de los ríos importantes que recorren nuestro país, bien con desembocadura en el mar Mediterráneo (Júcar y Turia) o bien en el Atlántico (Tajo). Esto ha sido señalado por diversos trabajos (De Luis et al., 2010; Miró, 2014) que llegan a señalar la progresiva ganancia de extensión territorial que experimenta el régimen de lluvias típicamente mediterráneo (máximo pluviométrico en otoño) desde el propio litoral mediterráneo hacia el interior de la península Ibérica, donde el pico principal de lluvias se sitúa generalmente en primavera (sector oriental de la Cordillera Ibérica).

Este hecho tiene una repercusión directa en la planificación hidrológica, puesto que las aguas de primavera son muy importantes para el desarrollo con normalidad de la actividad agraria y para la acumulación de reservas hídricas 
en embalses y acuíferos, que permitan atender el aumento del gasto en los meses cálidos del año. El futuro plan hidrológico nacional, que tendrá que redactarse en los próximos años en cumplimiento de la Directiva marco del agua y los ciclos de planificación hidrológica establecidos, debe tener en cuenta esta cuestión para evitar problemas de desabastecimiento coyuntural, teniendo en cuenta, además, que los modelos de cambio climático están señalando un probable incremento, en frecuencia de aparición y duración, de las secuencias de sequía en el área mediterránea. Como se ha señalado, unido a este hecho se está produciendo un aumento de los episodios de precipitaciones de alta intensidad horaria. Es decir, llueve menos días al año, pero lo hace de forma más concentrada. Los extremos pluviométricos (sequías e inundaciones) posiblemente se volverán aún más extremos y frecuentes. Este aspecto es importante para la planificación de infraestructuras hidráulicas en las ciudades, puesto que deben ir adaptándose a este incremento de los eventos de lluvias intensas, y especialmente al hecho de que dejan cantidades no muy abundantes pero muy concentradas en el tiempo. En media hora o una hora se acumulan 30 o 50 litros por metro cuadrado, lo que causa anegamientos y daños económicos y, en ocasiones también, pérdida de vidas humanas. Y todo porque nuestras ciudades litorales no están preparadas para asumir cifras importantes y concentradas de lluvia en tan poco rato. Como consecuencia, uno de los retos a los que se enfrentan los municipios del litoral mediterráneo español para las próximas décadas es la implantación de colectores de agua pluvial de gran capacidad.

Por su parte, el incremento de la temperatura media anual a nivel global es innegable, y el litoral mediterráneo español no es una excepción en este proceso. En el conjunto de observatorios de los territorios del Mediterráneo, entre Cataluña y las provincias mediterráneas de Andalucía, el aumento de temperaturas ha sido de $0,8{ }^{\circ} \mathrm{C}$ en los últimos cien años, con un ascenso muy pronunciado desde 1980. Sin embargo, la manifestación más evidente de la pérdida de confort térmico en esta región ha sido el incremento muy notable de las denominadas "noches tropicales», en las que el termómetro no desciende de $20^{\circ} \mathrm{C}$ durante toda la noche. Desde 1970 hasta la actualidad el número de noches tropicales en muchas ciudades de la región mediterránea se ha triplicado, puesto que ha pasado de 20 al año a unas 60 o 70 (y en algunos casos más) (figura 2). Además, desde el año 2000 se observa un aumento de noches en las que el termómetro no baja de $25^{\circ} \mathrm{C}$, e incluso en los últimos años ya se ha dado alguna jornada en la que la temperatura mínima diaria no ha descendido de los $29-30^{\circ} \mathrm{C}$. A las altas temperaturas nocturnas se suma la elevada humedad relativa en las localidades de la costa. Este último indicador tiene mucha importancia, puesto que con valores de humedad relativa del $70 \%$ o más, la temperatura que realmente siente el cuerpo humano es del orden de unos $4 \mathrm{a} 7^{\circ} \mathrm{C}$ mayor respecto a la que marca el termómetro. Este es el aspecto que genera una mayor pérdida de confort climático como consecuencia del calentamiento global en el área mediterránea.

Nos encontramos con varios factores que explican esta subida de los valores de temperatura mínima en nuestra región. En primer lugar, el ascenso térmico 
Figura 2. Evolución de las noches tropicales en Valencia, 1938-2018

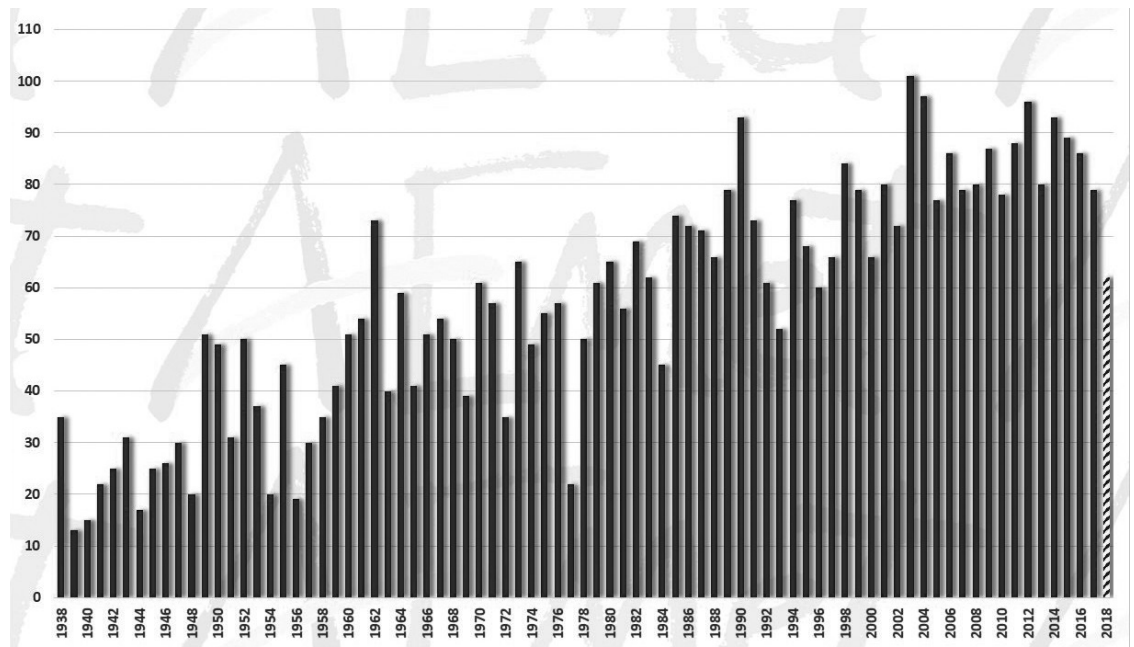

Fuente: AEMET.

como consecuencia del proceso de calentamiento global. Durante los últimos años se observa que el verano tiende a alargarse entre el final de la primavera y el principio del otoño en la fachada mediterránea. Otro factor a tener en cuenta es el citado aumento térmico del mar Mediterráneo, cuyas consecuencias más palpables son el incremento de las temperaturas mínimas y de la humedad relativa, así como variaciones en el régimen de las precipitaciones, especialmente en el litoral y el prelitoral valencianos. El último factor resulta determinante en el aumento de las temperaturas (especialmente nocturnas) en los núcleos de población del litoral y en aquellos de mayor tamaño. Nos referimos al efecto de la «isla de calor urbana», que modifica las características climáticas (temperaturas, precipitación, aparición de problemas de contaminación atmosférica, entre otros) a nivel local. El asfalto o el cemento retienen el calor del día, mientras que por la noche van perdiendo temperatura poco a poco y transmitiendo este calor al aire, situación que se va difuminando conforme nos vamos alejando del centro de la ciudad. En ocasiones, entre las afueras y el centro de un núcleo urbano, las diferencias pueden ser de 4 a $5^{\circ} \mathrm{C}$ e incluso más. Este fenómeno es más acusado en las ciudades del litoral mediterráneo, entre Barcelona y Málaga.

Por último, un dato muy relevante y una manifestación evidente del cambio en las condiciones climáticas de la costa mediterránea española es el aumento de la temperatura superficial del mar Mediterráneo. En efecto, sus aguas han experimentado un calentamiento en toda la cuenca, pero de modo singular en los extremos oriental y occidental de la misma. En el sector occidental los datos aportados por Pastor et al. (2018) muestran un calentamiento de $1,2^{\circ} \mathrm{C}$ entre 1980 y 2018 (figura 3). Esto significa que el calor acumulado en la 
Figura 3. Incremento de la temperatura del Mediterráneo occidental desde 1982

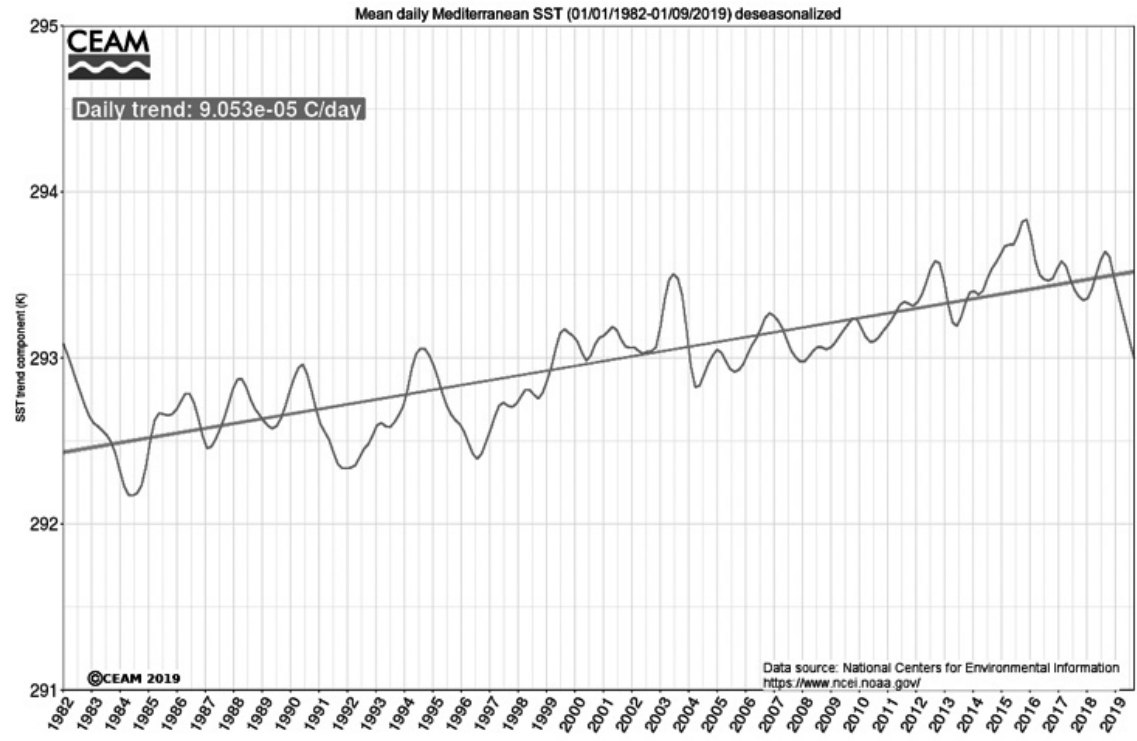

Fuente: $<$ www.ceam.es $>$.

cuenca marina es superior al propio calentamiento experimentado en el aire y registrado en los observatorios del litoral mediterráneo español.

El mar Mediterráneo, por tanto, es más cálido que hace tres o cuatro décadas, puesto que experimenta un proceso de acumulación de calor especialmente a partir de finales de primavera (mayo-junio), que se prolonga en verano hasta bien entrado el otoño (octubre y comienzos de noviembre). Resulta muy destacable que desde el año 2000 se hayan observado picos de hasta $30{ }^{\circ} \mathrm{C}$ durante el verano en las aguas próximas a Baleares y Argelia, un valor más propio de mares tropicales. En definitiva, el período anual en que hay aguas cálidas frente a las costas del Mediterráneo español es mucho mayor que hace unas décadas y además estas aguas están más calientes.

Este último hecho tiene una serie de consecuencias que repercuten sobre el clima de nuestra región. Por un lado, como se ha comentado en las líneas anteriores, un mar más cálido favorece el aumento de las noches tropicales en las poblaciones litorales, mientras que durante el día las brisas pueden contribuir a aumentar la sensación de bochorno, especialmente en aquellas jornadas en las que la temperatura del Mediterráneo alcanza o supera los $28{ }^{\circ} \mathrm{C}$ frente a nuestras costas, ya que el mar transmite el calor y la humedad al aire situado por encima de él. Por otro lado, esa mayor temperatura del mar supone un factor de riesgo ante posibles situaciones de inestabilidad asociadas a descuelgues de gotas frías o vaguadas de evolución retrógrada, ya que, entre otras cosas, el gradiente en la vertical tiende a ser mayor, así como una mayor evaporación, 
lo que unido a otros factores favorece que el calendario de lluvias intensas se extienda a otras épocas del año. Ya se ha señalado que el litoral mediterráneo puede registrar, como lo ha hecho, precipitaciones de alta intensidad horaria de vez en cuando en otras estaciones del año, no solo en otoño. Durante los últimos años hemos visto una cantidad no despreciable de eventos de lluvias fuertes en los meses de primavera, invierno e incluso en verano. Resulta reseñable el posible incremento de episodios de lluvias cálidas en el golfo de Valencia como consecuencia de la tropicalización del Mediterráneo.

Junto a estas evidencias que manifiestan ya los datos de los elementos climáticos en el litoral mediterráneo, quedan incertidumbres que la investigación deberá estudiar en los próximos años. La evolución de las precipitaciones es, sin duda, la incógnita importante, puesto que el calentamiento de la atmósfera y del mar Mediterráneo puede dar lugar a la formación más frecuente de nubosidad convectiva y de tormentas. Los modelos de cambio climático indican una reducción generalizada de las precipitaciones, lo que va a condicionar la circulación de agua en los ríos y su infiltración en los acuíferos. Así, por ejemplo, en las cuencas del Júcar y del Segura, así como en escenarios de emisión moderados, esta reducción se estima entre un 8 y un 10\% respecto a la actualidad hasta mediados del presente siglo. Hasta el momento presente, como se ha señalado, la tendencia de las últimas décadas acerca de esta cuestión es la de acumular cantidades de lluvia más destacadas en la franja litoral frente a los territorios del interior. Se muestra un incremento significativo en el sur de la provincia de Valencia y norte de Alicante, pero será necesario estudiar la evolución de este elemento climático en las próximas dos décadas, al menos, para confirmar las tendencias actuales en el conjunto del litoral mediterráneo. El viento es otro elemento de difícil modelización. No conocemos bien el comportamiento que pueden tener las brisas en una atmósfera más cálida y con un mar Mediterráneo también más caliente entre primavera y otoño. Por otra parte, los procesos de reajuste energético serán teóricamente más potentes en una atmósfera más cálida, y ello puede dar como resultado la formación de borrascas «enérgicas» de forma más habitual, que transiten por las latitudes ibéricas en su desplazamiento hacia el Mediterráneo, con lo que también se vería afectado el litoral mediterráneo por esta mayor presencia de vientos fuertes, y ello provocaría efectos en la actividad agraria y en el mobiliario urbano. Tampoco está claro el comportamiento de mecanismos de oscilación oceánico-atmosférica que afectan al territorio valenciano, como la NAO (Oscilación del Atlántico Norte) y la WeMO (Oscilación del Mediterráneo occidental), puesto que no se conoce la tendencia de los sistemas de presión a nivel de mar en unos mares más cálidos (Martin Vide y López Bustins, 2006). Si sigue la expansión hacia latitudes septentrionales de la célula de Hadley de nuestro hemisferio, nos podemos aproximar a un clima con cambios de estaciones mucho más difuminados y con presencia de dos momentos contrastados a lo largo del año: una estación más cálida, con desarrollo de tormentas, muy prolongada, y otra menos fría que la actual, que ocupará apenas uno o dos meses del año. Es decir, un clima mediterráneo aún más subtropicalizado. Pero este supuesto deberá corroborarse en las próximas décadas. 
En definitiva, el litoral mediterráneo español es un escenario idóneo para analizar el progreso y las consecuencias del calentamiento térmico actual, así como un laboratorio muy propicio para su estudio. Negar la evidencia del problema no aminorará su gravedad y ya tenemos datos que atestiguan que algo está pasando en nuestro clima. Por ello, este tiempo es básico para poner en marcha políticas y prácticas de reducción y de adaptación a los cambios que seguirá manifestando el calentamiento planetario en las próximas décadas. Algunos territorios del litoral mediterráneo (Cataluña) llevan años trabajando en esta cuestión, con participación de geógrafos en informes oficiales donde se han desarrollado diagnósticos rigurosos y propuestas de actuación. Otras regiones del mediterráneo español deben incorporarse a este proceso de elaboración de planes y estrategias de adaptación al cambio climático.

\section{3. ¿Hacia dónde deben ir los estudios del clima?: Una agenda para la climatología española en el contexto actual de calentamiento global}

La climatología española tiene una oportunidad importante de mostrar su carácter de disciplina geográfica de conocimiento cada vez más necesaria para el funcionamiento de la sociedad actual. El proceso actual de calentamiento global no deja margen para la duda científica ni para la necesidad de la acción sociopolítica. Y ahí debe estar la climatología española. Afortunadamente esto parece haberse entendido, si se analizan los trabajos que se publican en los últimos años en las revistas de impacto de temática climática o en las aportaciones que se presentan a los congresos internacionales y nacionales por parte de la geografía española.

A modo de agenda para el futuro próximo, los temas de estudio de la climatología española que se trabajan y que se van a seguir investigando en los próximos años están relacionados con los siguientes aspectos:

a) La modelización de elementos y procesos atmosféricos. La climatología española ha avanzado enormemente en el tratamiento de bases de datos y en su representación cartográfica, pero la coyuntura térmica actual exige dar un paso más y desarrollar modelos de comportamiento a medio y largo plazo de elementos y procesos climáticos que puedan determinar políticas ambientales y territoriales. Los modelos deben ser ponderados y basarse en datos reales, con resultados realistas, posibles y con alto grado de fiabilidad. Algunas posturas de rechazo respecto a la cuestión del cambio climático que surgieron en los primeros años de la actual hipótesis de efecto invernadero de causa antrópica procedían de la proyección exagerada que establecieron los primeros modelos climáticos incluidos en el primer informe del IPCC, con unos valores de subida térmica, con horizonte 2100 , demasiado elevados. Afortunadamente, desde entonces los resultados de la modelización climática de los siguientes informes del IPCC han ido ajustándose en estrecha relación con la mejora de los métodos de depuración y tratamiento de datos, así como de la selección de parámetros incluidos en dichos modelos (tabla 3). 
Tabla 2. Evolución del grado de fiabilidad de los modelos de cambio climático en los informes del IPCC

\begin{tabular}{lr}
\hline Informe IPCC & Fiabilidad \\
\hline $1 .^{\circ} 1990$ & $40 \%$ \\
$2 .^{\circ} 1995$ & $55 \%$ \\
$3 .^{\circ} 2001$ & $65 \%$ \\
$4 .^{\circ} 2007$ & $75 \%$ \\
$5 .^{\circ} 2013-2014$ & $85 \%$ \\
$6 .^{\circ}$ en fase de elaboración & est. $90 \%$ \\
\hline
\end{tabular}

Fuente: elaboración propia a partir de los informes del IPCC.

b) La monitorización de los impactos del proceso de calentamiento térmico planetario, necesaria para los procesos de ordenación del territorio y la planificación de nuevos usos en el suelo. La gestión territorial requiere información cada vez más precisa del medio físico para poder elaborar los modelos territoriales que determinarán el futuro de un espacio geográfico. Los aspectos climáticos presentes y futuros, en su comportamiento normal y extremo, son de obligada consideración en los documentos de ordenación territorial, en el marco del calentamiento climático actual (tabla 3).

c) La relación entre clima y salud, que ya están conociendo investigaciones de gran calidad realizadas por la geografía en nuestro país (Royé et al., 2019), se presenta como una temática de enormes posibilidades en los próximos años. A ello se unen los efectos previstos en la modelización climática (informes $4 .^{\circ}$ y $5 .^{\circ}$ del IPCC) respecto a la proliferación de consecuencias para la salud humana: aumento de olas de calor, fenómenos pluviométricos violentos y borrascas explosivas. Todo ello se une al aumento de la contaminación en áreas urbanas, debido a que no están surtiendo efecto - aún- los protocolos de reducción de gases de efecto invernadero por lo que respecta a la movilidad urbana (transporte por carretera) y a los sistemas de calefacción basados en el empleo de combustibles fósiles. De manera que el análisis, actual y futuro, de patrones atmosféricos con su consecuencia en los elementos climáticos y su relación con el desarrollo de afecciones de salud se configura como uno de los temas de mayor impacto para la climatología en el futuro.

d) Relaciones entre el agua y la atmósfera en la cuenca del Mediterráneo. Ya ha dado lugar al estudio de patrones de circulación atmosférica (WeMO), pero el calentamiento que está experimentando la cuenca del Mediterráneo, y en particular su sector occidental, está incidiendo en el comportamiento de algunos elementos climáticos con efectos ya destacados: patrones de precipitaciones y aumento de noches tropicales. Por otra parte, la relación entre el agua y la atmósfera se manifiesta también con efectos en la subida del nivel del mar y sus consecuencias en la franja costera. El informe sectorial del IPCC (IPCC, 2019) sobre los océanos y la criosfera manifiesta una gran preocupación por el efecto de subida del nivel del mar que ya se registra en áreas litorales de grandes 
Tabla 3. Incorporación de los estudios climáticos en los procesos de ordenación territorial: Situación actual y evolución en un contexto de cambio climático

\begin{tabular}{|c|c|c|c|}
\hline $\begin{array}{l}\text { Proceso } \\
\text { territorial }\end{array}$ & $\begin{array}{l}\text { Elemento climático a considerar } \\
\text { comportamiento normal } \\
\text { (y manifestación extrema) }\end{array}$ & $\begin{array}{l}\text { Comportamiento futuro } \\
\text { en latitudes medias }\end{array}$ & Medidas de adaptación \\
\hline $\begin{array}{l}\text { Planificación } \\
\text { territorial y } \\
\text { urbana }\end{array}$ & $\begin{array}{l}\text { - Temperatura (olas de calor } \\
\text { y de frío, noches tropicales). } \\
\text { - Precipitación (inundaciones } \\
\text { y nevadas). } \\
\text { - Viento (temporales viento). }\end{array}$ & $\begin{array}{l}\text { - Aumento de la irregularidad } \\
\text { y de la frecuencia de desa- } \\
\text { rrollo de eventos extremos. }\end{array}$ & $\begin{array}{l}\text { - Edificaciones (tejados verdes y aislamientos). } \\
\text { - Aumento de las zonas verdes (reducción de islas } \\
\text { de calor estival y zonas de sombra). } \\
\text { - Sistemas de evacuación de pluviales (SDUS, } \\
\text { parques inundables y depósitos pluviales). } \\
\text { - Desalojo de viviendas y equipamientos en } \\
\text { primera línea de costa. }\end{array}$ \\
\hline $\begin{array}{l}\text { Planificación } \\
\text { energética }\end{array}$ & $\begin{array}{l}\text { - Precipitación (sequías). } \\
\text { - Viento (temporales). } \\
\text { - Insolación para producción } \\
\text { energética solar. }\end{array}$ & $\begin{array}{l}\text { - Aumento de temporales } \\
\text { de viento (borrascas } \\
\text { explosivas) y de sequías. }\end{array}$ & $\begin{array}{l}\text { - Fomento de las energías limpias. } \\
\text { - Búsqueda de sistemas de abastecimiento } \\
\text { energético complementarios para evitar } \\
\text { efectos de sequías. }\end{array}$ \\
\hline $\begin{array}{l}\text { Planificación } \\
\text { hidrológica }\end{array}$ & $\begin{array}{l}\text { - Precipitación (inundaciones } \\
\text { y sequías). } \\
\text { - Temperatura (aumento de la } \\
\text { evaporación). }\end{array}$ & $\begin{array}{l}\text { - Aumento de la irregularidad } \\
\text { pluviométrica. }\end{array}$ & $\begin{array}{l}\text { - Planificación sostenible basada en fuentes } \\
\text { múltiples y de bajo impacto territorial. } \\
\text { - Superación del modelo basado en la oferta } \\
\text { continuada de agua. }\end{array}$ \\
\hline $\begin{array}{l}\text { Planificación } \\
\text { del litoral }\end{array}$ & • Viento (temporales). & $\begin{array}{l}\text { - Aumento de frecuencia } \\
\text { de temporales y borrascas } \\
\text { explosivas. } \\
\text { - Subida del nivel del mar. }\end{array}$ & $\begin{array}{l}\text { - Liberación de edificaciones del dominio } \\
\text { público (revisión de la Ley de costas 2013). } \\
\text { - Obras de infraestructura donde sean estricta- } \\
\text { mente necesarias. }\end{array}$ \\
\hline $\begin{array}{l}\text { Planificación } \\
\text { turística }\end{array}$ & $\begin{array}{l}\text { - Temperatura (olas de calor). } \\
\text { - Precipitación (inundaciones } \\
\text { y sequías). } \\
\text { - Viento (temporales). }\end{array}$ & $\begin{array}{l}\text { - Pérdida de confort climático } \\
\text { (Ta máxima y mínima). } \\
\text { - Climas más cálidos (pro- } \\
\text { longación de la temporada } \\
\text { cálida). } \\
\text { - Reducción de la innivación } \\
\text { (zonas de montaña). }\end{array}$ & $\begin{array}{l}\text { - Planificación urbana y edificación adaptada } \\
\text { al cambio climático. } \\
\text { - Acondicionamiento de sistema sanitario } \\
\text { (olas de calor). } \\
\text { - Reconversión de turismo de nieve. }\end{array}$ \\
\hline $\begin{array}{l}\text { Planificación } \\
\text { de los espacios } \\
\text { agrarios }\end{array}$ & $\begin{array}{l}\text { - Temperatura (olas de calor, } \\
\text { heladas) } \\
\text { - Precipitación (tormentas inten- } \\
\text { sas, inundaciones, sequías) } \\
\text { - Viento (temporales) }\end{array}$ & $\begin{array}{l}\text { - Aumento de temperaturas } \\
\text { y de la irregularidad de las } \\
\text { precipitaciones. } \\
\text { - Tormentas más intensas } \\
\text { y localizadas. }\end{array}$ & $\begin{array}{l}\text { - Adaptación de cultivos a cambios térmicos } \\
\text { y de precipitación (investigación agronómica). }\end{array}$ \\
\hline $\begin{array}{l}\text { Planificación } \\
\text { de los } \\
\text { sectores indus- } \\
\text { triales }\end{array}$ & $\begin{array}{l}\text { - Temperatura (olas de calor) } \\
\text { - Precipitación (ubicación instala- } \\
\text { ciones) }\end{array}$ & $\begin{array}{l}\text { - Aumento de la irregularidad } \\
\text { - Climosférica. } \\
\text { - Climas más cálidos. }\end{array}$ & $\begin{array}{l}\text { - Instalaciones adaptadas al calentamiento } \\
\text { climático (eficiencia energética). } \\
\text { - Nuevos tejidos adaptados a las nuevas } \\
\text { condiciones térmicas (investigación). } \\
\text { - Abandono de materiales plásticos. } \\
\text { - Ubicaciones industriales en áreas sin riesgo } \\
\text { natural. }\end{array}$ \\
\hline $\begin{array}{l}\text { Planificación } \\
\text { de zonas de } \\
\text { montaña }\end{array}$ & $\begin{array}{l}\text { - Temperatura (olas de calor) } \\
\text { - Precipitación (reducción inniva- } \\
\text { ción) }\end{array}$ & $\begin{array}{l}\text { - Descenso de innivación } \\
\text { (reconversión). } \\
\text { - Aumento de la irregularidad } \\
\text { atmosférica. }\end{array}$ & $\begin{array}{l}\text { - Reconversión de estaciones de esquí. } \\
\text { - Edificación adaptada a olas de calor más } \\
\text { frecuentes. } \\
\text { - Planificación hidrológica adaptada a sequías } \\
\text { más frecuentes. }\end{array}$ \\
\hline
\end{tabular}

Fuente: elaboración propia. 
cuencas oceánicas (Pacífico y Atlántico). Para la cuenca del Mediterráneo el problema no es tan evidente aún, pero en el informe se hace notar el efecto que tendrá la dilatación del agua del mar (calentamiento) y la frecuencia más elevada de temporales marítimos (temporales de levante en el litoral mediterráneo español) en la franja costera. Estas conclusiones han sido avaladas en el trabajo sobre efectos del cambio climático en las costas del mundo (Kulp y Strauss, 2019) y en el propio informe de los efectos del cambio climático en la costa española (Losada et al., 2014).

e) Por último, las escalas de detalle (comarcal y local) van a ir cobrando protagonismo en los estudios climáticos. La acumulación de población y las actividades en los núcleos urbanos y en los entornos metropolitanos nos exige detallar los resultados de los análisis climáticos para que sean útiles en la toma de decisiones en estas escalas. La climatología española tiene antecedentes de excelentes trabajos de escala local, especialmente para el estudio de la climatología urbana, desde los años ochenta. Las exigencias de la ciudadanía en materia climática, que demanda en mayor medida estudios y pronósticos de detalle, van a condicionar una proliferación de trabajos de este tipo de escala.

La climatología es la ciencia que, en mayor medida, recoge la esencia del objetivo científico de la geografía: el estudio de la actuación humana con sus diversas manifestaciones sobre la Tierra. No se puede entender el análisis del clima disociado del resto de elementos del medio natural y de su relación con los seres vivos y, en particular, con el ser humano, con sus actividades, con su forma de ocupar el territorio y con su propio bienestar y salud. Por la calidad de sus aportaciones, la climatología española compite en condiciones de igualdad con grupos e investigadores a escala internacional, pero con muchos menos medios económicos y equipamiento científico. La actual crisis climática debe convertirse en un eje de trabajo principal de la geografía en nuestro país, puesto que es la disciplina del cambio global, que tiene como elemento principal los cambios y las manifestaciones extremas que está experimentando la atmósfera en el proceso de calentamiento climático de causa antrópica actual. En este contexto, la climatología se encuentra en una posición destacada para liderar las investigaciones aplicadas sobre cambio climático, que es tanto como afirmar que puede convertirse en la rama geográfica matriz de la que dependan el resto de investigaciones de las diferentes especialidades de nuestra ciencia geográfica. Ahí está el reto.

\section{Agradecimientos}

A la revista Documents d'Análisi Geogràfica, a los departamentos de Geografía de las universidades de Girona y Autónoma de Barcelona, por su amable invitación a participar en el Día de la Geografía 2019, celebrado en la Universitat de Girona. Con enorme gratitud. 


\section{Referencias bibliográficas}

AEMET (2015). Proyecciones climáticas para el siglo XXI en España. Recuperado de $<$ http://www.aemet.es/es/serviciosclimaticos/cambio_climat>.

Barriendos i Vallvé, Mariano (2012). «La reconstrucción del clima a partir de testimonios históricos: Encrucijada metodológica entre la fuente cualitativa y su expresión numérica». Indice: Revista de Estadistica y Sociedad, 50, 18-20.

Brunet, Manola; Jones, Philip D.; Sigró, Javier; Saladié, Óscar; Aguilar, Enric; Moberg, Anders; Della-Marta, Paul M.; Lister, David; Walther, Alexander y López, Diego (2007). "Temporal and spatial temperature variability and change over Spain during 1850-2005». Journal of Geophysical Research: Atmospheres, 112, D12117. <https://doi.org/10.1029/2006JD008249>

Calvo García-Tornel, Francisco (2001). Sociedades y territorios en riesgo. Barcelona: Ediciones del Serbal.

- (2003). «Riesgos y vulnerabilidad en espacios urbanos». Mediterráneo Económico, 3, 425-443.

Camarasa Belmonte, Ana y Soriano García, Javier (2008). «Peligro, vulnerabilidad y riesgo de inundación en ramblas mediterráneas: Los llanos de Carraixet y Poyo». Cuadernos de Geografía, 83, 1-26.

CEDEX (2017). Evaluación del impacto del cambio climático en los recursos hídricos y sequias en España. Madrid: Ministerio de Agricultura y Pesca, Alimentación y Medio Ambiente / Ministerio de Fomento, 346 p.

Cuadrat, José María y Martín Vide, Javier (eds.) (2007). La climatología española: Pasado, presente y futuro. Zaragoza: Prensas Universitarias de Zaragoza, 574 p.

García Marín, Ramón (2008). «La sequía. De riesgo natural a inducido: El ejemplo de la Cuenca del Río Segura (Sureste de España)». Nimbus: Revista de Climatología, Meteorología y Paisaje, 21-22, 109-120.

García Marín, Ramón y Calvo García-Tornel, Francisco (2008). «Frecuencia y evolución de rachas secas en la cuenca del Guadalentín (sureste de España)». $B A G E, 48,71-89$.

Gil Guirado, Salvador y Pérez Morales, Alfredo (2019). «Variabilidad climática y patrones termopluviométricos en Murcia (1863-2017): Técnicas de análisis climático en un contexto de cambio global». Investigaciones Geográficas, 71, 27-54.

Giménez Font, Pablo (2009). "Cartografía histórica y alteración de cursos fluviales en la España mediterránea». En: Desastre natural, vida cotidiana y religiosidad popular en la España moderna y contemporánea. Coordinado por Armando Alberola Romá y Jorge Olcina Cantos. Alicante: Publicaciones de la Universidad de Alicante, $391-432$

González-Hidalgo, Juan Carlos; López-Bustins, Joan Albert; Stepanek, Petr; Martín-Vide, Javier y Luis, Martín de (2009). "Monthly precipitation trends on the Mediterranean façade of the Iberian Peninsula during the second half of the 20th century (1951-2000)». International Journal of Climatology, 29, 1415-1429.

Guerra Ángel, Pablo (2018). Clima i oratge a Ontinyent. Valencia: PUV, 150 p.

Ibisate, Askoa; Acín, Vanesa; Granado, David; Ballarín, Daniel; Sáenz de Olazagoitia, Ana; Ollero, Alfredo; Horacio, Jesús; Herrero, Xabier; Mora, Daniel; Elso, Josu y Rey, Kristian (2015). «Determinación de condiciones de referencia para la restauración de la morfología fluvial en ríos de Gipuzkoa». Actas del II Congreso Ibérico de Restauración Fluvial Restaurarios 2015. Pamplona, 245-253. 
Intergovernmental Panel on Climate Change (2019). IPCC Special Report on the Ocean and Cryosphere1 in a Changing Climate (SROCC). IPCC, 2019: Summary for Policymakers. En: Pörtner, H.-O.; Roberts, D.C.; Masson-Delmotte, V.; Zhai, P.; Tignor, M.; Poloczanska, E.; Mintenbeck, K.; Nicolai, M.; Okem, A.; Petzold, J.; Rama, B. y Weyer, N. (eds.). IPCC Special Report on the Ocean and Cryosphere in a Changing Climate. InGeneve, 1203 p. Recuperado el mes de noviembre de 2019, de <https://www.ipcc.ch/site/assets/uploads/sites/3/2019/11/ SROCC_FinalDraft_FullReport.pdf $>$.

Kulp, Scott A. y Strauss, Benjamin H. (2019). "New elevation data triple estimates of global vulnerability to sea-level rise and coastal flooding». Nature Communications, 10, 4844 . <https://doi.org/10.1038/s41467-019-12808-z>

López Bustins, Joan Albert; Martín-Vide, Javier y SÁnchez-Lorenzo, Arturo (2008). «Iberia winter rainfall trends based upon changes in teleconnection and circulation patterns». Global Planet: Change, 63 (2-3), 171-176.

Losada, Iñigo; Izaguirre, Cristina y Díaz, Pedro (2014). Cambio climático en la costa española. Madrid: Oficina Española de Cambio Climático. Ministerio de Agricultura, Alimentación y Medio Ambiente, 133 p. Recuperado el mes de noviembre de 2019, de <https://www.adaptecca.es/sites/default/files/documentos/2014_informe_c3e_final_cambio_climatico_en_la_costa_espanola.pdf $>$.

Luis, Martín de; BrunetTi, Michele; González-Hidalgo, Juan Carlos; Longares, Luis Alberto; MARTín-VIDE, Javier (2010). "Changes in seasonal precipitation in the Iberian Peninsula during 1946-2005». Global and Planetary Change, 74 (1), 27-33.

Martí Ezpeleta, Alberto; Taboada Hidalgo, Juan José; Royè, Dominic y Fonseca Blanco, Xavier (2019). O tempos e o clima de Galicia. Vigo: Edicións Xerais. Básicos Ciencia, 216 p.

Martín Vide, Javier (2007). «La importancia de los estudios históricos en el análisis de riesgos climáticos». En: Riesgos naturales y desarrollo sostenible: Impacto, predicción y mitigación. Coordinado por Francisco Javier Ayala Carcedo, Jorge Olcina Cantos, Luis Laín Huerta y África González Jiménez. Madrid: IGME, 159-166.

Martín Vide, Javier y Gallego, José Luis (2009). Apaga la luz: El libro sobre el cambio climático. Barcelona: Davinci Continental.

Martín Vide, Javier y López Bustins, Joan Albert (2006). "The Western Mediterranean Oscillation and rainfall in the Iberian peninsula». International Journal of Climatology, 26 (11), 1455-1475.

$<$ https://doi.org/10.1002/joc.1388>

Martínez Fernández, Luis Carlos y Olcina Cantos, Jorge (2019). "La enseñanza escolar del tiempo atmosférico y del clima en España: Currículo educativo y propuestas didácticas». Anales de Geografía de la Universidad Complutense, 39 (1), $125-148$.

Massey, Doris (2004). «Lugar, identidad y geografías de la responsabilidad en un mundo en proceso de globalización». Treballs de la Societat Catalana de Geografía, 57, 77-84.

Millán, M. M.; Estrela, M. a José y Miró, Juan Javier (2005). «Rainfall components: Variability and spatial distribution in a Mediterranean area (Valencia region)». Journal of Climate, 18 (14), 2682-2705. <https://doi.org/10.1175/JCLI3426.1>

Miró PÉrez, Javier (2014). Downscaling estadístico de series climáticas mediante redes neuronales: Reconstrucción en alta resolución de la temperatura diaria para la Comu- 
nidad Valenciana. Interpolación espacial y análisis de tendencias (1948-2011). Alicante: Universidad de Alicante. Tesis doctoral. <https://doi.org/10.13140/RG.2.1.2059.1523>

Miró, Juan Javier; Estrela, M. ${ }^{a}$ José y Barberá, M. ${ }^{a}$ José (2012). «Análisis de tendencias de series diarias de temperatura a partir de un downscaling estadístico con datos de reanálisis y redes neuronales: Aplicación a la Comunidad Valenciana». En: Rodríguez Puebla, Concepción; Ceballos, Antonio; González, Nube; Morán, Enrique y Hernández, Ascensión (eds.). Cambio climático: Extremos e impactos. Madrid: Publicaciones de la Asociación Española de Climatología (AEC), A-8, 549-560.

Miró Pérez, Juan Javier; Estrela Navarro, M. ${ }^{a}$ José y Olcina Cantos, Jorge (2016). «Reconstrucción de la señal térmica local en la Comunidad Valenciana entre 1948 y 2011 a partir de un downscaling estadístico mediante una red neuronal artificial: Detección de patrones locales de cambio». BAGE, 70, 113-147.

Monjo, Robert y MARTÍn-VIDE, Javier (2016). "Daily precipitation concentration around the world according to several indices". International Journal of Climatology, 36 (11), 3828-3838. $<$ https://doi.org/10.1002/joc.4596>

Morote Seguido, Álvaro y Moltó Mantero, Enrique (2017). «El Museo del Clima de Beniarrés (Alicante): Propuesta de un recurso didáctico para la enseñanza de la climatología». Didáctica de las Ciencias Experimentales y Sociales, 32, 109-132.

Murray, Warwick E. (2005). Geographies of Globalization. Londres y Nueva York: Routledge, 420 p. Routledge Contemporary Human Geography Series.

Nederveen Pieterse, Jan (2015). Globalization and Culture: Global Mélange. 3. a ed. Lanham: Rowman \& Littlefield, 196 p. Globalization.

Olcina Cantos, Jorge (1996). «El clima: Factor de diferenciación espacial. Divisiones regionales del mundo desde la antigüedad al s. XviII». Investigaciones Geográficas, $15,79-98$.

- (2008). «Cambios en la consideración territorial, conceptual y de método de los riesgos naturales». Scripta Nova: Revista Electrónica de Geografía y Ciencias Sociales. Barcelona: Universidad de Barcelona, XII (270), 24. Recuperado de <http:/www. ub.es/geocrit/sn/sn-270/sn-270-24.htm>.

- (2012). «De los mapas de zonas afectadas a las cartografías de riesgo de inundación en España». Anales de Geografía de la Universidad Complutense, 32 (1), 91-131.

- (2017). «Incremento de episodios de inundación por lluvias de intensidad horaria en el sector central del litoral mediterráneo español: Análisis de tendencias en Alicante». Semata, 29, 143-163.

Olcina Cantos, Jorge y Baños Castiñeira, Carlos (2004). "Los fines de la geografía». Investigaciones Geográficas, 33, 39-62.

Olcina Cantos, Jorge; Hernández Hernández, María; Rico Amorós, Antonio Manuel y Martínez Ibarra, Emilio (2010). "Increased risk of flooding on the coast of Alicante (Region of Valencia, Spain)». Natural Hazards, 10 (11), 2229-2234.

Olcina Cantos, Jorge y Moltó Mantero, Enrique (eds.) (2019). Climas y tiempos del Pais Valenciano. Alicante: Publicaciones de la Universidad de Alicante.

Ollero Ojeda, Alfredo (2015). "Un necesario cambio de visión y de estrategia en la gestión de las inundaciones». Tecnoaqua, 12, 122-124.

Paneque, Pilar (2015). «Drought Management Strategies in Spain». Water, 7 (12), 6689-6701. 
Pastor, Francisco; Valiente, José Antonio y Palau, José Luis (2018). «Sea Surface Temperature in the Mediterranean: Trends and Spatial Patterns (1982-2016)». Pure and Applied Geophysics, 175, 4017-4029. <https://doi.org/10.1007/s00024-017-1739-z>

Peña-Gallardo, Marina; Gámiz-Fortis, Sonia Raquel; Castro-Díez, Yolanda y Esteban-Parra, María Jesús (2016). «Análisis comparativo de índices de sequía en Andalucía para el periodo 1901-2012». Cuadernos de Investigación Geográfica, 42, 67-88. <http://dx.doi.org/10.18172/cig.2946>

Pérez Morales, Alfredo (2012). «Estado actual de la cartografía de los riesgos de inundación y su aplicación en la ordenación del territorio: El caso de la Región de Murcia». Boletín de la Asociación de Geógrafos Españoles, 58, 57-82.

Pérez Morales, Alfredo; Gil Guirado, Salador y García Martín, Francisca (2015). "Veinte años de protección de cauces en el litoral de la Región de Murcia (11942014): Evaluación de la eficiencia de las medidas de Ordenación del Territorio». Anales de Geografía de la Universidad Complutense, 35 (1), 169-185.

Pérez Morales, Alfredo; Navarro Hervás, Francisca y Álvarez Rogel, Yolanda (2016). «Propuesta metodológica para la evaluación de la vulnerabilidad social en poblaciones afectadas por el peligro de inundación: El caso de Águilas (Murcia, sureste ibérico). Documents d'Anàlisi Geogràfica, 62 (1), 133-159. <https://doi.org/10.5565/rev/dag.242>

Perles Roselló, M. Jesús y Cantarero Prados, Francisco (2010). «Problemas y retos en el análisis de los riesgos múltiples del territorio: Propuestas metodológicas para la elaboración de cartografías multi-peligros». Boletín de la Asociación de Geógrafos Españoles, 52, 245-271.

Perles Roselló, M. a Jesús y Mérida Rodríguez, Matías (2010). «Patrón territorial y conformación del riesgo en espacios periurbanos: El caso de la periferia este de la ciudad de Málaga». Scripta Nova: Revista Electrónica de Geografía y Ciencias Sociales, 14, 323-339.

Pita López, M. a Fernanda (2014). «La respuesta de la sequía hidrológica a la sequía pluviométrica en las cuencas mediterráneas españolas». En: Cambio Climático y Cambio Global. Madrid: Publicaciones de la Asociación Española de Climatología (AEC), 411-425.

Quereda-Sala, José; Montón-Chiva, Enrique y Escrig-Barberà, José (2009). «El cambio climático en las regiones de Valencia y Murcia: La sombra analítica de un auténtico troyano». Investigaciones Geográficas, 49, 107-127. <https://doi. org/10.14198/INGEO2009.49.06>

Redolat, Darío; Monjo, Robert; López-Bustins, Joan A. y Martín-Vide, Javier (2018). «Upper-Level Mediterranean Oscillation index and seasonal variability of rainfall and temperature». Theoretical and Applied Climatology, 135, 1059-1077. <https://doi.org/10.1007/s00704-018-2424-6>

Ribas, Anna y Saurí, David (2006). «De la geografía de los riesgos a las geografías de la vulnerabilidad». En: Nogué, Joan y Romero, Juan (eds.). Las otras geografías. Valencia: Tirant lo Blanch, 285-299. Colección Crónica.

Royé, Dominic; Zarrabeitia, M.a Teresa; Fernández de Arroyabe, Pablo; Álvarez Gutiérrez, Álvaro y Santurtún, Álvaro (2019). "Papel de la temperatura aparente y de los contaminantes atmosféricos en los ingresos por infarto agudo de miocardio en el norte de España». Revista Española de Cardiología, 72 (8), 634-640. 
Saurí Pujol, David (2009). "Agua y modelos de desarrollo urbano». Agua, territorio y paisaje. De los instrumentos programados a la planificación aplicada: V Congreso Internacional de Ordenación del Territorio. Coordinado por Luciano Sánchez PérezMoneo y Miguel Ángel Troitiño Vinuesa, 93-104.

Saurí, David; Olcina, Jorge; March, Hug; Martín-Vide, Javier; Vera, F.; Padilla, Ernest y Serra-Llobet, Anna (2013). "Tourism, Climate Change and Water Resources: Coastal Mediterranean Spain as an Example». En: European Climate Vulnerabilities and Adaptation: A Spatial Planning Perspective. Nueva York: John Wiley \& Sons. Ltd. Editors: Philipp Schmidt-Thomé, Stefan Greiving, 231-252.

Sebastiá-Alcaraz, Rafael y Tonda-Monllor, Emilia (dirs.) (2017). Enseñanza y aprendizaje de la geografía para el siglo XXI. Alicante: Publicaciones de la Universidad de Alicante, $221 \mathrm{p}$.

Segura Beltrán, Francisca (2009). "Geomorfología, inundaciones y alteración antrópica del espacio inundable: El caso del río Girona (Alacant, octubre de 2007)». Boletín de la Asociación de Geógrafos Españoles, 49, 83-103.

Serrano Notivoli, Roberto (2017). Reconstrucción climática instrumental de la precipitación diaria en España: Ensayo metodológico y aplicaciones. Zaragoza: Universidad de Zaragoza. Facultad de Filosofía y Letras. Departamento de Geografía y Ordenación del Territorio, 234 p. + anexo cartográfico. Tesis doctoral inédita.

Sigró Rodríguez, Javier; Brunet India, Manola y Aguilar Anfrons, Enric (eds.) (2008). Cambio climático regional y sus impactos. Tarragona: Publicaciones de la Asociación Española de Climatología (AEC), serie A, n. ${ }^{\circ}$ 6. Artyplan, 823 p.

- (2009). «El desarrollo de datos de calidad y el cambio térmico observado en España». Investigaciones Geográficas, 49, 89-107.

Tejedor Vargas, Ernesto (2017). Climate variability in the northeast of Spain since 17 th century inferred from instrumental and multiproxy records. Zaragoza. Universidad de Zaragoza. Tesis doctoral inédita.

Vicente-Serrano, Sergio; Azorín-Molina, César; Peña-Gallardo, Marina; Tomàs-Burguera, Miquel; Domínguez-Castro, Fernando; Martín-HernánDez, Natalia; Beguería, Santiago; Kenawy, Ahmed El; Noguera, Iván y García, Monica (2019). "A high-resolution spatial assessment of the impacts of drought variability on vegetation activity in Spain from 1981 to 2015». Natural Hazards and Earth System Sciences, 19, 1189-1213.

<https://doi.org/10.5194/nhess-19-1189-2019> 